\title{
Cardiovascular imaging 2017 in the International Journal of Cardiovascular Imaging
}

\author{
Johan H. C. Reiber ${ }^{1}$
}

Published online: 23 June 2018

(c) Springer Nature B.V. 2018

For several years we have had a partnership with the European Society of Cardiovascular Radiology (ESCR). Recently this has been more formalized, also in the sense that the ESCR will contribute to the leadership of the International Journal of Cardiovascular Imaging. In particular this means that the following positions will be created for the ESCR:

Adjunct Editor ESCR

Prof Matthias Gutberlet, University of Leipzig - Heart Center, Germany

Additional Assoc Editor MR Prof Luigi Natale, Catholic University of Rome, Italy

Additional Assoc Editor CT Prof Joachim Lotz, Medical University of Göttingen, Germany
Additional Editorial Board members:

Prof Marco Francone, Sapienza University, Rome, Italy Prof Christian Loewe, Medical University Vienna, Austria

Prof Birgitta Velthuis, University Medical Center Utrecht, Netherlands

Prof Rodrigo Salgado, University Hospital Antwerp, Belgium

I look very much forward to work with this excellent team to further grow the readership of the International Journal of Cardiovascular Imaging.

Johan H. C. Reiber, PhD Editor-in-Chief 